\title{
Escritura y modernidad del libro amorfo: \\ El suicida de Alfonso Reyes \\ y Motivos de Proteo de José Enrique Rodó
}

\author{
Writing and modernity \\ of the amorphous book: \\ El suicida by Alfonso Reyes \\ and Motivos de Proteo by José Enrique Rodó
}

Sergio Ugalde Quintana*

Resumen: En este artículo se analiza la importancia que tuvo el libro de José Enrique Rodó Motivos de Proteo (1909) en la escritura de El suicida (1917) de Alfonso Reyes. En un principio se indaga el espacio de enunciación del texto del mexicano; después se revisan las principales recepciones críticas del libro; posteriormente se destaca el contexto filológico en el cual Reyes escribió este volumen; y finalmente se propone que el modelo fluctuante, abierto y en constate movimiento que proporcionó Motivos de Proteo a El suicida conforma el carácter moderno de esta escritura.

Palabras clave: Alfonso Reyes, José Enrique Rodó, Ensayo.

ABSTRACT: This article analyses the importance of José Enrique Rodó's Motivos de Proteo (1909) in Alfonso Reyes' writing of El suicida (1917). Such analysis begins exploring the enunciation space of the Mexican author's text. Then, it looks at the book's main critical receptions. Afterwards, it highlights the philological context in which Reyes wrote this volume. Finally, this study suggests that the fluctuating, open and constant motion model which gave Motivos de Proteo to El suicida defines the modern nature of this writing.

Key words: Alfonso Reyes, José Enrique Rodó, Essay.

Recepción: 20 de febrero de 2018

Aceptación: 4 de abril de 2018

cela-fFyl-unam (sugalde@hotmail.com). 
EL LUGAR DE ENUNCIACIÓN: LA COLECCIÓN

CERVANTES, MUY MODERNA Y VANGUARDISTA

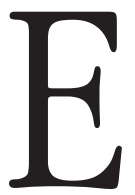

127 de septiembre de 1916, Alfonso Reyes, en esos momentos en Madrid, escribió una carta a su amigo Martín Luis Guzmán, donde daba pormenores de los proyectos que en esos días realizaba: además de la traducción de Ortodoxia de Chesterton, que aparecería poco después en la editorial Calleja, el joven mexicano estaba enfrascado en la escritura de un libro de ensayos. "He tenido que encerrarme medio mes para acabar mi traducción de Ortodoxia chestertoniana [...]. En el entreacto, he escrito un volumen de 200 páginas con motivo del suicidio de Trigo, que se llama El suicida: veremos si hay un editor que se atreva." (1991: 98). Estas líneas sorprenden por varias razones. En principio, por la cercanía del evento detonador de la escritura del libro. Felipe Trigo, abundante y populoso autor de novelas naturalistas, se había pegado un tiro en Madrid el 2 de septiembre de ese año - apenas tres semanas antes de que Reyes diera noticia a Martín Luis Guzmán de su proyecto ensayístico- - En segundo lugar, llama la atención que el ensayista dude de la posibilidad de encontrar un editor para su libro. Sobre este segundo aspecto me gustaría detenerme un poco.

Una propuesta editorial, pese a las dudas expresadas, muy pronto llegó a Reyes. Justo a mediados de 1916 se había instalado en Madrid un antiguo profesor de la Escuela Nacional Preparatoria, y entusiasta animador de los proyectos del Ateneo de la Juventud, Luis G. Urbina. El poeta de inmediato se asoció a una empresa cultural dirigida por el escritor español Francisco Villaespesa. El proyecto que ambos impulsaron fue: Cervantes. Revista mensual ibero-americana. En este órgano de difusión, que comenzó a aparecer en agosto de 1916, se publicaron textos de figuras como Antonio Machado, Ricardo Rojas, Amado Nervo, Vargas Vila, el propio Felipe Trigo, José Ingenieros y José Enrique Rodó (Valera 1998: 63-90; García de la Concha 1981: 409-424). El ambiente del modernismo campeaba poderosamente en los primeros números de esta publicación. El proyecto cultural, sin embargo, no sólo consistía en dar a conocer un 
mensuario. Muy pronto, los directores de la publicación (Villaespesa, Ingenieros y Urbina) sacaron a la luz una colección de libros. Así, en noviembre de 1916, según consta en las inserciones informativas de la revista, ya se habían publicado, en la "Colección Cervantes", 4 títulos, todos ellos de autores americanos: La cultura filosófica en España de José Ingenieros; Bajo el sol y frente al mar de Luis G. Urbina, Geometría moral de Juan Montalvo y Cuentos frágiles de Manuel Gutiérrez Nájera. Algún resabio del proyecto hispanoamericanista de principios del siglo XX se percibía en los trabajos de esta empresa editorial. ${ }^{1}$ Es lógico que Urbina se acercara a Reyes para proponerle publicar su reciente volumen en este espacio. Así, el quinto número de la "Colección Cervantes" fue precisamente El suicida de Alfonso Reyes. En el número de marzo de 1917, la revista Cervantes publicó, como adelanto del libro en prensa y al lado de colaboraciones de Rafael Heliodoro Valle, Gabriela Mistral, el ensayo que daba título al volumen del mexicano (Reyes 1917: 65-85).

Si bien Cervantes fue en un principio un órgano identificado con el movimiento modernista, muy pronto, en 1919, con la llegada de Rafael Cansinos Assens a la dirección del mensuario, la publicación abrió sus páginas a las colaboraciones de los portavoces del movimiento de vanguardia. Al cabo de tres años, en la revista se publicaba tanto a las figuras más sobresalientes del modernismo como a los representantes vanguardistas. Poemas de José Juan Tablada aparecían junto a los manifiestos de Tristan Tzara; prosas de Ingenieros, al lado de versos de Vicente Huidobro. Este escenario artístico e intelectual, propiciado por las publicaciones de la revista Cervantes, configura el espacio y el tiempo en los cuales se articula la enunciación del libro de Alfonso Reyes. En él se manifiestan varias tensiones; la principal de ellas es el reajuste de una estética finisecular con los nuevos proyectos artísticos de inicios del siglo Xx. No es gratuito, entonces, que la escritura misma de El suicida esté atravesada por esos impulsos. Eso se confirma en el cuerpo textual del volumen.

1 Sobre el movimiento hispanoamericanista en España, que resaltaba la idea de una comunidad cultural y espiritual entre la antigua metrópoli y los territorios americanos, véanse Mainer 2004: 125-180; Pike 1971: 1-72; Niño Rodríguez 1993: 15-48. 


\section{LAS PRIMERAS LECTURAS}

El suicida apareció publicado en Madrid el 7 de abril de 1917. De inmediato, tal como ya lo había hecho con su primera recopilación de ensayos, Reyes se dio a la tarea de distribuir su nuevo volumen entre las personas que conocía. Si su primer libro, Cuestiones estéticas (1911), había representado una apuesta crítica por fundar un discurso filológico moderno en México, ${ }^{2}$ El suicida, por el contrario, era un intento por escapar del universo agobiante de la filología.

Entre los primeros personajes que recibieron el libro se encontraban algunos amigos madrileños, mexicanos y americanos en Europa. En una carta dirigida a Pedro Henríquez Ureña, fechada el 4 de mayo de 1917, Reyes deja ver los interlocutores a los que envió su volumen. Ahí se perciben las primeras reacciones críticas:

Pruebas de El Suicida que ya habrás recibido. Azorín ni me ha acusado recibo; Ventura Calderón me ha puesto un telegrama felicitándome; Foulché-Delbosc me ha dicho que tiene la seguridad de que no hay en la Península quien sea capaz de escribir así, y asombrado de que pueda reunir yo a mi literatura mi dedicación erudita. Apenas comienzo a distribuir mi libro, y tú has recibido el que me dio la imprenta. Mi hermano Rodolfo está encantado. Enrique Mesa dice que también; Icaza me ha dicho cosas afectuosas y vagas, creo que él no puede entender mi libro. Pérez Ayala, que siempre me está elogiando, no ha tenido aún tiempo de leerlo, y mi

2 Son pocos los trabajos que han analizado el carácter fundacional de Cuestiones estéticas en el campo intelectual y disciplinar mexicano de esos años. Robert Conn, en un trabajo pionero, ha definido el proyecto filológico de Reyes como la apuesta por fundar un estado estético en los albores del porfiriato (2002: 81-112). Otro artículo que también se propone una lectura de este libro en función de la renovación disciplinar de los estudios literarios en el México de inicios del siglo xx es Ugalde 2016: 155-173. Muchos críticos se han detenido en señalar el ambiente idealista que permeaba la atmósfera intelectual de principios del siglo xx en Hispanoamérica; sin embargo, casi nadie ha llamado la atención sobre la importancia que jugó el universo disciplinar filológico para varios de los jóvenes intelectuales y ensayistas de ese momento; entre ellos, Pedro Henríquez Ureña, Alfonso Reyes y Francisco García Calderón. La forma del ensayo en estos tres últimos puede verse en tensión y en disputa con el universo legitimador de la filología. 
amigo Canedo ha enmudecido completamente. Has de saber que aquí todavía se asustan. No ganaré un céntimo, pues es negocio de Urbina (hoy en la Argentina, Legación Fabela), y Villaespesa (hoy en México, Virginia Fábregas) (1981: 45).

Algunos personajes respondieron al envío de Reyes con cartas. Fue el caso de Enrique González Martínez, Miguel de Unamuno, José Vasconcelos, Eugenio D’Ors y Pedro Henríquez Ureña. ${ }^{3}$ Entre todas esas primeras reacciones, que ya marcan las intensas redes intelectuales que Reyes creó a lo largo de su vida, me gustaría destacar una de ellas. Se trata de la opinión del costarricense Joaquín García Monge quien, en una carta fechada el 2 de septiembre de 1917 y albergada en la Capilla Alfonsina, destacaba algunas características de la escritura del libro dignas de señalar:

Mi querido amigo: con algún retraso (porque ahora el servicio de correo anda mal) recibí su Suicida y la traducción de Chesterton. Ambos libros me han hecho sumo contento y de ello le quedo muy agradecido. En sus ensayos trabaja a la inglesa: sobrios, elegantes, profundos, icuán pocos saben hacer eso en nuestra América! Y sugieren muchas reflexiones. Y señalan otros puntos de vista. Algo que me agrada mucho es la manera tan graciosa y placentera de hacer uso de la sabiduría y el ingenio de los buenos autores españoles. En esto también señala usted un camino: los autores españoles vistos no por el lado de la nueva erudición, sino por el otro, que es más fecundo, por lo que hacen pensar y sentir.

La carta de García Monge apuntaba, como centro de la primera recepción de la obra, la forma de la escritura. Encontraba en ella algo novedoso e intentaba situar el libro dentro de una tradición. Fue así que asoció el volumen del mexicano con el ensayismo inglés. Esta misma línea de argumentación se confirma en otros comentarios de la época. Según asienta el propio Reyes en su Historia documental de mis libros, El suicida fue reseñado por Martín Luis Guzmán, Federico de Onís y Xavier Icaza; todos

3 Al respecto pueden revisarse los epistolarios de esos personajes albergados en el Archivo Histórico de la Capilla Alfonsina. Algunos fragmentos de esas cartas han sido citados por Reyes 1990: 222-240 y por Pineda 2015: 103-131. 
ellos alabaron el carácter novedoso de la escritura. El caso de Xavier Icaza es ejemplar al respecto. En su reseña, publicada en marzo de 1918 en el periódico El Pueblo, aseguraba:

Es (El suicida) una novedad en nuestra literatura. Habla de la tragedia humana, pero la observa a la manera inglesa, sin ampulosidad y sin tono solemne ni pedantería... Un ensayo puede estudiar un asunto hasta agotarlo, y ninguna época ha necesitado tanto como la nuestra, conocer mil pormenores para formar después una síntesis y construir un ideal. Un ensayo hace esto y puede hacerlo, lo que es mejor, de modo ligero en apariencia, haciendo amena la lectura, volviendo un punto árido a primera vista, agradable y placentero $(1919: 7,17)$.

Las opiniones de Federico de Onís apuntaban en este mismo sentido, pues aseguraba que el volumen de Reyes era "the best book of essays of the English type writen in Spanish" (Reyes 1990: 227). Algo se destaca en los testimonios anteriores: el carácter novedoso de la escritura ensayística de El suicida provenía de la forma inglesa de tratar los asuntos. El propio regiomontano, en carta del 10 de diciembre de 1916 a Henríquez Ureña, llegó a asegurar la pervivencia chestertoriana en su volumen: "El suicida [...]. Se parece mucho a Chesterton y no me gusta" (Reyes 1981: 36). Sin embargo, tras esta aparente tradición inglesa, hay una escritura, del ámbito hispanoamericano, que detonó la forma de proceder del libro.

\section{EL CUERPO AMORFO DEL LIBRO}

El suicida está compuesto por 11 ensayos, todos ellos escritos en el lapso de ocho años (el más antiguo databa de 1909 y el más cercano se redactó en los primeros días de abril de 1917, justo cuando la mayor parte del libro ya estaba en la imprenta). Los temas eran diversos. Sin embargo, bajo la apariencia de los múltiples asuntos, una cierta unidad de concepción se mantenía entre todos ellos. El punto de arranque era el suicidio de Felipe Trigo. A partir de ahí, el ensayista tejía y destejía sus ideas sobre las posibles razones que habían llevado a alguien, con el suficiente éxito 
editorial para vivir de las regalías de sus novelas, a quitarse la vida. De esta manera, Reyes trataba, en los siguientes ensayos, sobre la reafirmación de la libertad del ser humano, sobre el poder creador de su espíritu crítico y su carácter rebelde, sobre la fuga como inspiración creadora, sobre el impulso vital como el origen de las acciones de la humanidad. Con cada uno de estos subtemas, el ensayista mostraba un panóptico - un "mosaico", dice él-de sus preocupaciones vitales.

En varios momentos del libro, Reyes concibe el procedimiento de sus ensayos como una libre divagación que surge, avanza, se extravía y regresa al núcleo de partida. Por eso, James Willis Robb ha caracterizado la técnica discursiva de El suicida como la de un laberinto en el que se cruzan y enmarañan las reflexiones (1965: 261); Sebastián Pineda la ha definido como una elipsis (2015: 103). Pese a este carácter amorfo —más adelante volveré sobre esto-, es evidente que los temas centrales son: la actitud vital y rebelde ante el mundo y la potencia creativa del ser humano en el ejercicio de su libertad. De hecho, la segunda gran recepción crítica de este libro, gestada a inicios del siglo XXI, señala como punto central su carácter libertario y rebelde. Así, Evodio Escalante, en un trabajo clave para entender las relaciones entre rebeldía y conciencia crítica en Reyes, ha sugerido que en los textos de El suicida se configura una idea de crítica basada en nociones del romanticismo alemán (2005: 43-58). Ignacio Sánchez Prado, al analizar el texto "La sonrisa", ha sostenido que el carácter libertario del libro se relaciona, análogamente, con una protesta ante el establecimiento de una cultura oficializada de los años del carrancismo. Para Sánchez Prado, el volumen plantea "una concepción de la cultura y, específicamente, de la literatura, fundada en el inconformismo y la rebeldía" (2012: 39). El vínculo entre El suicida y la dimensión política e histórica de México es muy pertinente; sin embargo, hay otra vía que puede complementar esa interpretación. Me refiero a las nociones de libertad y de rebeldía como respuestas a los rigores de la escritura filológica que Reyes experimentaba en esos momentos en Madrid, en el Centro de Estudios Históricos. En este sentido, Robert Conn ha señalado que El suicida incorpora la filología hispánica y "overcomes the categories of his colleagues by identifying philosophic 
and literary modernity with the ethos of nonelite romantic subjects located in the past or in archaic, picturesque present" (2002: 134). La relación entre rebeldía y disciplina, que experimenta Alfonso Reyes en la escritura de este libro, llevan a pensar en la dupla que Michel Foucault estableció entre verdad y poder, entre disciplina y política. Todo saber disciplinar y todo disciplinamiento es también un ejercicio de poder (1996: 139-230). Contra esa disciplina Reyes se rebela.

En todo caso, me parece que es necesario leer la reivindicación vitalista y creativa del hombre, presente en El suicida, como una respuesta y una protesta ante los poderes normalizadores - estabilizadores- del trabajo y lo cotidiano, en el contexto específico de la vida que Alfonso Reyes llevaba en esos momentos en Madrid. En el periodo de escritura de El suicida, Reyes ejercía varios trabajos para sobrevivir: era traductor, articulista de diarios, colaborador de revistas; pero, sobre todo, filólogo en el Centro de Estudios Literarios. A partir de principios de 1914, Reyes se integró como miembro regular de la sección de filología del Centro de Estudios Históricos bajo la guía de Ramón Menéndez Pidal, y al lado de Américo Castro, Federico de Onís y Tomás Navarro Tomás. Ahí permaneció y trabajó, de forma intensa y constante, hasta 1919. Sus numerosas y valiosas contribuciones al universo de la filología han sido puestas de relieve recientemente por Mario Pedrazuela (2015: 445-468). Muy pronto el trabajo del filólogo y la actitud del ensayista entraron en conflicto. Así lo notó el hispanista francés Ramond Foulché-Delbosc quien, en respuesta al envío del libro El suicida, respondió a Reyes, entre sorprendido e intrigado, el 23 de abril de 1917:

¿El suicida? Sí señor, llegó sin novedad a este rinconcito hispánico, y tres noches seguidas, antes de descansar, leí capítulo tras capítulo. Ensayos, sí: tengo la seguridad de que no hay en la Península quien los pueda escribir. Libro que hace pensar. iy cuidadito si son numerosas las gentes que necesitan semejante aguijón! Veremos lo que dicen los señores críticos. ¿Sabe V. lo que me sorprende más? Pues entiendo con dificultad cómo la misma persona puede dedicarse al mismo tiempo a la erudición y a escribir ensayos como éstos (Reyes 1956: 98). 
En esta carta, Foulché-Delbosc distinguió de forma clara la tensión central que la escritura de Reyes experimentaba en esos momentos. Por un lado, estaba el trabajo riguroso y erudito, propio de la disciplina filológica; por otro, la escritura libre del ensayo, que apelaba al libre divagar de la conciencia. El primero era "objetivo"; el segundo, abiertamente "psicológico". Reyes era muy consciente de esta tensión. Un ejemplo de ello es la carta enviada a Ramón Gómez de la Serna, con fecha del 15 de mayo de 1916: "En mí hay un Jekyll que hace filología y un Hyde que escribe con tinta de varios colores" (Pineda 2015: 88). No sorprende, entonces, que el joven escritor mexicano se quejara constantemente de las formas de proceder y de escritura impuestas en el Centro de Estudios Históricos. En específico, la correspondencia con su amigo Pedro Henríquez Ureña es un testimonio fehaciente. En ellas se muestra a un Reyes que sufre el disciplinamiento del saber:

En todas tus cartas recuérdame los nombres de estos dos enemigos del alma: 1. la humildad, 2. la filología (28 de diciembre 1915) [...]. Los discípulos de M. Pidal han exagerado la "escuela" y se olvidan de que su maestro tiene alas cuando quiere. Han dado a la Revista un carácter impersonal, seco, brutal, simbólico y esquemático (7 de febrero de 1916) [...]. Yo, en tanto, comido de deudas y de filología [ ...] ya no leo, no pienso, no escribo sobre lo que quisiera. Acabaré por desaparecer (25 de mayo de 1916) [...]. Pedro: si tú haces que Huntington me regale un millón de dólares, me comprometo ante mis dioses a ser el primer escritor del habla castellana. Pero mientras tenga que hacer todo el día y toda la noche filología de cuistre y gramática de fracasado, no es posible, señor, no puede ser (21 de agosto de 1916) (Reyes 1981: 125-164).

Las quejas del joven escritor no son muy distintas de las que Leo Spitzer, un profesional de la disciplina, manifestó años después al referirse a la extrema aridez de los estudios filológicos. ${ }^{4}$ Frente a ese mundo rígido

4 Al describir la situación de la disciplina y reflexionar sobre el sentido de la filología entre los años treinta y cuarenta, Leo Spitzer se quejaba del carácter impersonal, positivista y acumulativo de muchas publicaciones del momento: "Was wunder, dass deutsche Geistesgeschichte seit Dilthey am philologischen Betrieb der ameri- 
y disciplinado, la escritura de El suicida representó la reafirmación de la libertad. La dedicatoria del libro es reveladora al respecto: "Imposible dedicar estas caprichosas divagaciones a los amigos nuevos. Reservemos para ellos las obras objetivas, y volvamos los ojos a la patria, y demos -es irremediable - sobre los infortunados amigos viejos" (Reyes 1980: 302). En este paratexto, ubicado al final del volumen y escrito poco antes de que el libro se terminara de imprimir, Reyes evidencia las tensiones que su escritura vivía en ese periodo. Los nuevos amigos del Centro de Estudios Históricos, atareados en las rígidas, sistemáticas y "objetivas" labores de la filología, no podían ser los interlocutores de $E l$ suicida. Es evidente, por lo tanto, que el entorno en el cual se escriben las divagaciones ensayísticas de Reyes está marcado por el ejercicio profesional de la disciplina. El Suicida nace, entonces, en el contexto de la filología, pero también, como el Nacimiento de la tragedia de Nietzsche, contra la filología. ${ }^{5}$

kanischen Universität fast spurlos vorübergegangen ist, dass dieser prinzipiell noch immer in den Bahnen des deutsch-französichen Positivismus der Siebziegerjahre wandelt (Biographismus, Quellensuche, Statistik, Katalogiesieren, Bibliographie), und dass an keine Beschneidung der anarchistichen und relieflosen, in den vielen Zeitschriften verstreuten Publikationen gedacht wird - Publikationen, die den Typus der dingbesessenen Anmerkungswissenschaft entsprechen, keinen beruflichen oder weltanschaulichen Muss entspringen und das Hervortreten von erlesenen Problemen und Forscherpersönlichkeiten verhindern" (1946: 582). "Sorprende que la historia intelectual alemana desde Dilthey haya pasado casi sin dejar vestigios en la actividad filológica de la universidad americana; y que en principio esa actividad todavía esté atada a los dictámenes del positivismo franco alemán de los años de 1870 (biografismo, búsqueda de fuentes, estadísticas, catalogación, bibliografía), y que no se piense en recortar la proliferación de publicaciones anárquicas y sin contornos diseminadas en muchas revistas-, publicaciones que responden a un tipo de ciencia, de notas a pie de página, obsesionada por cosas, sin origen ni necesidad profesional ni vinculada a una visión del mundo, y que impiden el surgimiento de problemas y de personalidades científicas destacadas" (la traducción es nuestra).

5 Sobre la importancia de las lecturas de la obra de Nietzsche en el joven Alfonso Reyes, véanse Quintanilla 2002: 619-663, Quintanilla 2008: 113-126. Robert Conn también ha señalado la relevancia de la lectura nietzscheana en el primer libro de Reyes, Cuestiones estéticas, de 1911 (2002: 81-112). 
Desde un inicio, un problema central se presentó a Reyes: la unidad del libro. Así, en carta a Vasconcelos, del 12 de febrero de 1918, aseguraba: "Debo comenzar por manifestarte que este libro no tiene verdadera unidad". El mismo sentimiento sería expresado ocho años después cuando, en su carta a dos amigos, Enrique Díez-Canedo y Genaro Estrada, aseguraba: "(El suicida) es un libro no del todo cosido, donde los diversos elementos no acaban de casar entre sí: se notan suturas y remiendos" (Reyes 1995: 477). Incluso al final de su vida, al redactar su Historia documental de mis libros, Reyes no fue indulgente con este volumen y manifestó su escepticismo sobre la posibilidad siquiera de considerarlo como un proyecto acabado. Esta desconfianza sobre el sentido orgánico del volumen fue tematizado en uno de los ensayos de El suicida. Ahí se encuentra una reflexión fundamental para entender su idea de escritura ejercida en ese momento.

Según testimonio del propio Reyes, cuando el volumen ya estaba en prensa, los impresores le pidieron más textos para hacer crecer el ejemplar: "Cuando se imprimía El suicida, a última hora, la imprenta (M. García y Galo Sáenz, Mesón de Paños) me pidió que añadiera algo al original para darle más cuerpo al libro. Entonces, entre lo que ya tenía por ahí y lo que pude emborronar prontamente, aderecé el 'Monólogo del autor', y también la 'Dedicatoria', que por ir al fin más bien equivale al 'Envío' de las antiguas baladas" (Reyes 1990: 223-224). Es posible imaginar que la capilla del libro tenía bastante espacio en blanco, así que Reyes, muy diligente, se dio a la tarea de llenarla. El ensayista escribió de prisa, y a vuelo de pluma, unas notas que incluyó como parte de la última "divagación" del libro. El ensayo conformado por esos apuntes se titula: "Monólogo del autor". Ahí, el escritor medita sobre las características del texto que acaba de terminar: "Se ha formado un libro, casi de por sí: amorfo, balbuciente como un monólogo de sonámbulo. Hijo extraño de mis noches, hay que bautizarlo y bendecirlo" (1980: 293). Justo después de esta arenga por un buen bautizo del volumen, Reyes comienza una reflexión central para entender el proyecto de El suicida. Ahí señala las dos posibles formas de 
titular un volumen: la primera consiste en nombrarlo por su temática; la segunda "pretende sugerir, no el asunto, sino el proceso con que lo ha seguido el pensamiento; el dinamismo del espíritu (que supone una complicada elaboración de la facultad crítica)" (Reyes 1980: 294). Esta última manera fue la que Reyes asumió para nombrar su libro de ensayos. Es entonces cuando aparece una alusión reveladora sobre la impronta que una forma de escritura ejerció en el joven mexicano en esos momentos:

Justo ha sido llamar Motivos de Proteo al libro "abierto sobre una perspectiva indefinida", al libro entendido como trasunto fiel de los múltiples estados de ánimo, expresión sucesiva del movimiento de la conciencia; es decir: el libro sin más arquitectura que la arquitectura misma de nuestras almas - musicalidad infinita que hubiera deleitado a Wagner. Un Proteo es el ánimo, nadie lo sujeta, y vuela a todas partes, sin finalidad aparente, por el gusto de su ejercicio: motivos de ese Proteo serán, pues, los libros hechos como por mero desahogo; motivos de ese Proteo, pues encierran el vario y mudable revolar del pensamiento en todos los rumbos de su espacio sin dimensiones. Pero no sólo se trata aquí de una manera de bautizar los libros, sino de una cuestión estética, de una completa teoría del libro, que, emanada de Rodó, está produciendo en la viña de América una floración de obras, buenas y malas. Esta nueva teoría del libro merece capítulo aparte (1980: 294).

El párrafo resulta elocuente por sí mismo. Es indudable que en $E l$ suicida están presentes ciertas formas del ensayismo inglés. Sin embargo, la idea de libro amorfo, del libro abierto, del libro que discurre como una conciencia en movimiento - que divaga, se pierde, regresa, articula fragmentos, recuerda historias - proviene, en primer lugar, de la escritura de Motivos de Proteo de José Enrique Rodó.

\section{UNA PERSPECTIVA INDEFINIDA}

La presencia del Ariel en toda la generación del Ateneo de la Juventud ha sido destacada por numerosos críticos (García Morales 1992; Castro 2000: 91-110; Cesana 2016); sin embargo, el influjo que tuvo Motivos de 
Proteo en esos mismos jóvenes no ha sido señalado lo suficiente. Y no es que haya sido menor. Por el contrario, el señalamiento de Reyes marca las dimensiones del evento. En este libro de Rodó, el joven mexicano encontró un modelo formal para una modernidad literaria; el procedimiento de una escritura multiforme que representaba una conciencia fluctuante, proliferante y en movimiento.

Motivos de Proteo no se dio a conocer al público como una obra orgánica y acabada, sino como un fragmento de otro proyecto más extenso y en perpetua elaboración. El nombre de ese proyecto original era: Proteo. ${ }^{6}$ Según Emir Rodríguez Monegal, Rodó planeó esa obra primigenia en cinco libros y una introducción. Lo que finalmente se publicó en 1909, y que llevó por nombre Motivos de Proteo, tenía como base el libro V de aquel proyecto original. Esta parte se refería a la evolución de la personalidad. Las condiciones de elaboración dieron a este texto un carácter "decididamente fragmentario". Rodó era consciente de esto; por eso, en un paratexto que se encuentra al inicio del volumen, asentó:

No publico una primera parte de Proteo: el material que he apartado para estos Motivos da, en compendio, una idea general de la obra harto extensa (aun si la limitase a lo que tengo escrito) para ser editada de una vez. Los claros de este volumen serán el contenido del siguiente; y así en los sucesivos. Y nunca Proteo se publicará de otro modo que de éste; es decir: nunca le daré arquitectura concreta, ni término forzoso: siempre podrá seguir desenvolviéndose, viviendo. La índole del libro (si tal puede llamársele) consiente, en torno de un pensamiento capital, tan vasta ramificación de ideas y motivos, que nada se opone a que se haga de él lo que quiero que sea: un libro en perpetuo devenir, un libro abierto sobre una perspectiva indefinida (1967: 308-309).

Este inacabamiento y creación perpetua del libro no siempre fue percibido de forma positiva. Emir Rodríguez Monegal, por ejemplo, concluía que Motivos de Proteo

6 Sobre la génesis, la concreción, los manuscritos y las notas póstumas de este magno proyecto, véase Ibáñez 1967: 7-52. 
Es, no cabe duda, [la] [...] obra más ambiciosa [de Rodó]. Pero es, también y en más de un sentido, una obra incompleta y fragmentaria. Contiene tal vez sus mejores páginas aisladas, pero es irregular. Su filosofía no cala hondo ni explota las nuevas perspectivas que descubre. Al coleccionar tanto ejemplar dispar, tanta anécdota, tanta variación infinitesimal del humor o del destino, Rodó no pareció advertir que muchas veces se le escapa lo que pone en movimiento ese animado muestrario (1967: 308).

Desde un inicio, Rodó tomó conciencia de la novedad formal de su proyecto. Hacia 1904, cuando ya tenía una versión bastante avanzada del libro, describió Motivos de Proteo a dos de sus principales interlocutores del momento: Miguel de Unamuno y Juan Francisco Piquet. Al primero le decía, en carta del 20 de marzo de 1904:

Tengo casi terminado mi libro, que probablemente haré imprimir en Madrid o Barcelona. Es extenso. El tema (aunque no cabe indicarlo con precisión en breves palabras) se relaciona con lo que podríamos llamar la "conquista de uno mismo": la formación y el perfeccionamiento de la propia personalidad; pero desenvuelto en forma muy variada, que consiente digresiones frecuentes, y abre amplio espacio para el elemento artístico. Será un libro, en cierto modo, a la inglesa, en cuanto a los caracteres de la exposición, que pueden tener parecido con la variedad y relativo desorden formal de algunos 'ensayistas' británicos. Veremos qué resulta (1967: 1393).

Algo muy similar había comentado unos días antes, en carta del 6 de marzo de 1904, a su amigo Juan Francisco Piquet:

Cuando el tiempo y el humor no me faltan, sigo batiendo el yunque de Proteo, libro vario y múltiple como su propio nombre; libro que, bajo ciertos aspectos, recuerda (o más bien recordara) las obras de los "ensayistas" ingleses, por la mezcla de la moral práctica y filosofía de la vida con el ameno divagar, las expansiones de la imaginación y las galas de estilo; pero todo ello animado y entendido por un soplo "meridional", ático, o italiano del Renacimiento; y todo unificado, además, por un pensamiento fundamental que dará unidad orgánica a la obra, la cual, tal como yo la concibo y procuro ejecutarla, será de un plan y de una índole enteramente nuevos en la literatura de habla castellana, pues participará de la naturaleza de varios 
géneros literarios distintos (v. g. La didáctica, los cuentos, la descripción, la exposición moral, y psicológica, el lirismo), sin ser precisamente nada de eso y siéndolo todo a la vez (1343-1344).

El proceso de elaboración de este libro implicó para Rodó un trabajo de filigrana. Recolectó citas, trabajó las frases con detenimiento, armó cuadernos con todos sus apuntes. En fin, organizó materiales durante años para proponer una escritura breve y proliferante. Como bien lo ha estudiado Ottmar Ette, la isotopía central del libro es el cambio perpetuo. Esta característica está presente desde el título mismo de la obra. El término "Motivos" "acentúa el carácter fluctuante, dinámico y multiforme" del volumen. La constante transformación se confirma en las primeras frases del primer fragmento: "Reformarse es vivir ... Y desde luego, nuestra transformación personal en cierto grado, ino es ley constante e infalible en el tiempo? ¿Qué importa que el deseo y la voluntad queden en un punto si el tiempo pasa y nos lleva? El tiempo es el sumo innovador" (Rodó 1967: 309). Estos elementos dan a Motivos de Proteo la fisonomía de una obra abierta que no tiene comienzo ni fin. En ella se ramifican las ideas y los motivos. El objetivo no es presentar un ente orgánico y unitario sino "una estructuración proliferante y descentrada, que podríamos calificar de rizomática" (Ette 2000: 185). El texto está constituido por 158 capítulos; cada uno de ellos no sobrepasa las tres páginas. Ahí se articulan, como ya lo señalaba la carta dirigida a Piquet, varios géneros. En ellos se propone un intenso diálogo intertextual a partir de las numerosas citas y alusiones (Real de Azúa 1976: 69). Esta recolección de citas es "tanto una técnica de trabajo (con sus cuadernos y sus hojas sueltas) como un procedimiento narrativo y discursivo a nivel de una escritura deliberadamente multiforme y 'heterogénea' que permite impresionantes saltos cronológicos y digresiones temáticas" (Ette 2000: 189). El libro resulta ser así una máquina textual en la que "todos los motivos establecen relaciones mutuas y abiertas". De esta manera, la autobiografía espiritual que Rodó imaginó para Motivos de Proteo, representa, antes que a un "yo" completo, el "simulacro de un sujeto": 
El mito de Proteo [...] condujo a Rodó a la construcción de un texto hecho de muchos textos, de un libro hecho de muchos libros. Proteo de Motivos, José Enrique Rodó supo crear un libro virtualmente ilimitado en cuyos claros se van ubicando los árboles que producirán nuevas hojas, arrastradas por nuevos motivos, nuevas motivaciones girando "alrededor de sí mismas, como poseídas danzantes”. En esta gimnástica del alma, la figura de Proteo queda idéntica a sí misma, es decir, a sus transfiguraciones "en mil formas diversas". Solo en este sentido, creo, Rodó hubiera aceptado considerar sus Motivos como una auto-biografía: como la vida que se escribe a sí misma (Ette 2000: 202).

La peculiaridad de esta escritura fue muy atractiva para Alfonso Reyes. De ahí que, al reflexionar sobre el ejercicio ensayístico que había realizado en el libro El suicida, el joven escritor mexicano señalara como origen de su proyecto la forma fragmentaria, proliferante, desbordada y múltiple de Motivos de Proteo. En ella encontró un modelo de modernidad literaria adecuada a sus intenciones. En específico, el procedimiento de una conciencia que avanza, reflexiona, duda y trata de asir el objeto de sus divagaciones, resultó el centro de sus intereses.

MODERNIDAD DEL LIBRO AMORFO

La libertad, la rebeldía, la crítica, la voluntad de creación están presentes en todos y cada uno de los once ensayos que conforman El suicida. Sin embargo, la temática es tratada de forma peculiar. Lo que interesa a Reyes es el procedimiento de la conciencia que, en su libre divagar, cerca, acecha e intenta asir la materia de sus reflexiones. A Reyes le interesa mostrar el procedimiento de la conciencia al reflexionar sobre varios fenómenos: la vida, la libertad, la rebeldía y la muerte. En este procedimiento no se define un sujeto del conocimiento sino la multiplicidad de las voces. A Reyes, en esta peculiar epistemología, no le importa la identidad sino la pluralidad interna. Nadie es solo un yo. Todos somos una multitud de personajes. Al igual que en Rodó, la apuesta del ensayista mexicano es mostrar los simulacros del sujeto: sus distintos disfraces y la posibilidad de una articulación múltiple 
de sus discursos. En algún momento asegura: "Y, en todo caso, iquién no es interiormente múltiple?" Esta proliferación discursiva es la respuesta al orden que establecen las instituciones y las costumbres, una protesta contra el disciplinamiento de los saberes. Por eso, no es gratuito que, al hablar de esa necesidad psicológica de no ser solo uno, sino una multitud, Reyes traiga a cuento el ejemplo que ya había dado Gómez de la Serna para justificar su, al menos, doble vida-escritura: la del filólogo y la del ensayista: "Los casos de doble personalidad no son un misterio; proceden - dice la ciencia - de una fatiga. Son una escapatoria, una fuga [...]. El impecable Dr. Jekyll se escapa periódicamente de sí mismo; busca a media noche el escondite de Mr. Hyde, y sale de él transfigurado" (1980: 246-247). Pero el hombre no es solo una dupla, sino una variedad, un coro de perspectivas: "Y en cada hombre hay varios: uno que afirma, otro que niega, otro que a ambos los admira, el que de todos juntos se ríe, y otro - iel último? - que a todos los justifica y se echa a dormir después tranquilamente" (247). Este principio de proliferación identitaria marca profundamente la formalización de la escritura de Reyes. Los ensayos de El suicida configuran, como los Motivos de Proteo, acechanzas breves de una conciencia que se transforma y se ramifica. Las estrategias de esa escritura proliferan: lo mismo redacta un fragmento de media página, que un párrafo de tres cuartillas donde se contienen citas, alusiones, micro-historias, aforismos, diálogos, interrogantes. De ahí que el punto fundamental, en términos de la formalización de la escritura, sea la transformación, la renovación, la mudanza, el movimiento. El suicida, podríamos asumir, es el caso de una escritura en movimiento.? "El hombre no quiere aceptar; lo que quiere el hombre es innovar, desde innovarse a sí mismo hasta el ambiente." Estas palabras de Reyes no distan mucho del "Vivir es reformarse" de Rodó.

Para Reyes, justo al final de su ejercicio ensayístico de El suicida, hay dos maneras - dos teorías - de entender la conformación de un libro: la manera clásica o artística y la manera moderna o psicológica. La primera apela a una forma del discurso acabada, precisa y con límites; la segunda,

Sobre la noción de literatura en movimiento y su vínculo con los procesos de una modernidad vertiginosa y acelerada, véase Ette 2001: 9-20. 
a un fluir constante del espíritu, a una escritura en perpetuo devenir. El libro artístico es forma estática; el libro psicológico es movimiento y dinamismo. El primero transmite la simetría, la lucidez, la belleza plástica, al estabilidad; el segundo, los múltiples y difusos estados de ánimo de una conciencia reflexiva.

El artista, como el creador del mundo, debe ante todo crear formas: así se engendra la retórica. Los libros escritos conforme a sus leyes tenían, propiamente, pies y cabeza. La retórica se divide en géneros: el deliberativo, el judicial, el demostrativo. La literatura, en fuerza de clasificaciones, viene a ser una especie de historia natural [...]. Pero nuevas corrientes cruzan la lente alterable del espíritu, y los artistas combinan diversamente, en el tiempo, los elementos de la herencia común. En fin, se juzga que la manifestación literaria es, como la materia misma, cosa dinámica. La conciencia estática de la antigua psicología se pone a correr como una montaña de hielo que se funde en un río, y la literatura, que es su expresión, trata de imitarla. La manifestación literaria [...] nada tiene de común con las formas, con los sólidos. La retórica, pues, la preceptiva, pierden toda su autoridad; la poesía se olvida de la estrofa y de las leyes métricas, y nadie respeta ya las tradicionales partes del discurso. Los libros dejan de tener principio y fin: son una perspectiva indefinida donde el espíritu causa su versatilidad esencial (295).

Las características del libro psicológico al que apela Reyes, y que emanan de la concepción de Rodó, tienen también un secreto parecido con el procedimiento que, años después, el propio ensayista desarrollaría en su obra máxima de teoría literaria. Me refiero a El deslinde y a lo que Reyes definió ahí como la fenomenología del ente fluido. El discurrir de la conciencia, y la descripción de sus estados de ánimo, remiten a ese proceder que Reyes estableció, en un principio, como fenomenológico y, después, resultado de las acervas críticas de los profesionales de la filosofía, designó como fenomenográfico. ${ }^{8}$ Justo al inicio del ensayo "Nuevas dilucidaciones

8 Sobre la recepción negativa que tuvo El deslinde entre Juan David García Bacca, Edmundo O'Gorman y Gabriel Méndez Plancarte, véase Rangel 1993: 87-107. Cabe señalar que estos comentarios llevaron a Reyes a cambiar el término "fenomenología" (Reyes 1944: 18) por "fenomenografía" (Reyes 1963: 31) para designar el procedimiento asumido en El deslinde. 
casuísticas", Reyes asegura: "He hablado de las teorías de la aceptación, y, tratando de definir mi preferencia por las teorías de rebeldía, he descrito, de paso, muchos de sus aspectos, como se describen siempre aspectos de uno y otro campo cuando se practica un deslinde" (1980: 262) (subrayado mío). Para entender este procedimiento de la conciencia que deslinda los temas y los objetos es necesario remitirse a una de las lecturas básicas de Reyes en esos momentos: William James. En varios pasajes de El suicida aparece mencionado este filósofo inglés que ya había dado las fuentes para una perspectiva vitalista entre los miembros del Ateneo de la Juventud. A decir de Robert Conn, Reyes retomó de este filósofo una hemenéutica fisio-psicológica "based upon the mental and physical energies of the individual" (2002: 82). El psicologismo de James se complementó, años después, con la noción de la fenomenología del ente fluido que Reyes sostenía en El deslinde: "El estudio del fenómeno literario es una fenomenología del ente fluido. En esta mudanza incesante, en este mar de fugaces superficies, no es dado trazar rayas implacables" (Reyes 1944: 18). Esta fluctuación líquida, esta incierta demarcación, que Reyes señala para acercarse al fenómeno de lo literario, recuerda el carácter acuático del Proteo. Lo que importa no es la rigidez, la estabilidad y la definición, sino el ondular de las inestabilidades, la fugacidad de lo vivido, y ipor qué no? la opacidad (Glissant 1990: 204), lo incierto, de la experiencia literaria. "En este vaivén - dice Reyes- hay culminaciones y depresiones de la onda, pero no siempre se pueden fijar pesos específicos permanentes... Nuestra atención se divide en dos series de observaciones paralelas: lo literario y lo no literario; el movimiento del espíritu, y el dato captado por ese movimiento; la noética o curso del pensar, y la noemática o ente pensado; la puntería y el blanco; la ejecución expresiva y el asunto significado" (1944: 18-19). El curso del pensar, que se manifiesta como el movimiento del espíritu, tiene sus orígenes en el proceder asumido por el ensayista joven que publicó El suicida bajo el influjo de la escritura rodoniana.

Podríamos señalar, por lo tanto, que los ensayos de El suicida pueden ser considerados en dos niveles. Por un lado, como la reafirmación del espíritu rebelde y crítico de Alfonso Reyes que se subleva frente al carácter 
positivista que le exigían las labores técnicas de la sección de filología del Centro de Estudios Históricos. Por otro lado, pueden ser considerados como el inicio de una forma de indagación en la que la conciencia busca sus objetos, se envuelve en ellos, se torna ellos mismo, los describe y los entrega al lector como un hecho inseparable. Todo esto se enmarca en la reivindicación de la vitalidad como elemento central de la creación. La vida da el carácter específico, fluctuante, en movimiento, que caracteriza las ideas y la prosa - la formalidad lingüística - en la cual se nos entrega el libro de Reyes y en la cual juega un papel importante la presencia de los Motivos de Proteo. Rodó había establecido que su libro se abría como la vida; fluctuaba como el devenir; iba y venía como las olas. Un libro así era la imagen perfecta de una obra amorfa, irregular, incierta, pero al mismo tiempo abierta al paseo de la conciencia del sujeto que está a la caza de sus objetos. Todo esto nos remite nuevamente al espacio de enunciación desde el cual se dio a conocer El suicida. Tal como sucedía con la revista Cervantes, donde la tensión de las escrituras modernistas y vanguardistas convivían, en El suicida se engranan y potencian las enseñanzas proteicas de José Enrique Rodó y la posibilidad de un libro ensayístico fluido, amorfo, dinámico, inestable y moderno.

BiBLIOGRAFíA

CAstro Morales, BelÉn. "Introducción”. José Enrique Rodó. Ariel. Madrid: Cátedra, 2000. 11-135.

Cesana, Raffaele. José Enrique Rodó en México. Tesis de doctorado. México: UNAM, 2016.

CONn, ROBERT. Politics of Philology. Alfonso Reyes and the Invention of the Latin American Literary Tradition. Lewisburg: Bucknell University Press, 2002.

ESCAlanTe, EVODio. Las metáforas de la crítica. México: UAm/Gedisa, 2015. 43-58. 
ETTe, OtTMAR. “Una gimnástica del alma’: José Enrique Rodó, Proteo de Motivos". Ottmar Ette y Titus Haydenreich (eds.).José Enrique Rodó y su tiempo. Cien años de Ariel. Madrid: Vervuert/Iberoamericana, 2000.

Literatur in Bewegung. Raum und Dynamik grenzüberschreitenden Schreibens in Europa und Amerika. Gotinga: Vielbrück Wissenschaft, 2001.

FOUCAuLT, MiCHEL. Vigilar y castigar; nacimiento de la prisión. Trad. Aurelio Garzón del Camino. México: Siglo XXI, 1996.

García de la CONCHA, Víctor. "Dos revistas cervantinas en las primeras escaramuzas de la vanguardia". Homenaje a Gonzalo Torrente Ballester. Madrid: Caja de Ahorros y Monte de Piedad de Madrid, 1981. 409-424.

García Morales, ALFONSO. El Ateneo de México (1906-1914). Orígenes de la cultura mexicana contemporánea. Sevilla: Escuela de estudios Hispanoamericanos, 1992.

Glissant, Édouard. Poétique de la relation. Poétique III. París: Gallimard, 1990.

IBÁÑEZ, ROBERTO. "El ciclo de Proteo". Cuadernos de Marcha (mayo de 1967): 7-52.

ICAZA, XAVIER. "Notas sobre Alfonso Reyes". El Pueblo. México, 17 de febrero de 1919. $7 \mathrm{a}, 17 \mathrm{a}$.

MAINER, JosÉ CARLOS. La doma de la quimera. Ensayos sobre nacionalismo y cultura en España. Madrid: Iberoamericana/Vervuert, 2004.

Niño RodríGuEZ, ANTONio. "Hispanoamericanismo, regeneración y defensa del prestigio nacional (1898-1931)". Pedro Pérez Herrero y Nuria Tabanera (comp.). España-América Latina: un siglo de políticas culturales. Madrid: Asociación de Investigación y Especialización sobre temas Iberoamericanos, 1993. 15-48.

Pedrazuela Fuentes, Mario. "Alfonso Reyes y la filología: entre la "Revista de Filología Española" y la "Nueva Revista de Filología Hispánica". Nueva Revista de Filología Hispánica 63 (2015): 445-468. 
PIKE, FReDericK B. Hispanismo, 1898-1936. Spanish Conservatives and Liberals and their relations with Spanish America. Londres: University of Notre Dame, 1971.

Pineda Buttrago, Sebastián. El exilio creador: la obra literaria de Alfonso Reyes en España (1914-1924). Tesis de doctorado. México: El Colegio de México, 2015.

Quintanilla, Susana. "Dioniso en México o cómo leyeron nuestros clásicos a los clásicos griegos". Historia Mexicana 51 (2002): 619-663. "Nosotros". La juventud del Ateneo de México. México: Tusquets, 2008.

RANGel GueRra, Alfonso. Las ideas literarias de Alfonso Reyes. México: El Colegio de México, 1993.

Real de AzÚa, Carlos. "Prólogo a Motivos de Proteo". José Enrique Rodó. Ariel, Motivos de Proteo. Caracas: Biblioteca Ayacucho, 1976.

Reyes, Alfonso. "El Suicida (del último libro de Alfonso Reyes)". Cervantes. Revista mensual ibero-americana (marzo de 1917): 65-85. - El deslinde. México: El Colegio de México, 1944. . "Correspondencia entre Raymond Foulché-Delbosc y Alfonso Reyes". Ábside. Revista de cultura mexicana (enero-marzo de 1956): 14-105.

$17-422$.

."El suicida". Obras completas. Vol. 3. México: FCE, 1980. 217-303. Epistolario intimo. Pedro Henríquez Ureña/Alfonso Reyes. Vol. 2. Santo Domingo: Universidad Nacional Pedro Henríquez Ureña, 1981.

"Historia documental de mis libros". Obras completas. Vol. 24. México: FCE, 1990. 149-356.

Guzmán/Reyes. Medias palabras. Correspondencia 19131959. Fernando Curiel editor. México: UnAm, 1991.

. "Carta a dos amigos". Obras completas. Vol. 4. México: FCE, 1995.

RoBB, James WiLlis. El estilo de Alfonso Reyes (imagen y estructura). MéxiCO: FCE, 1965. 
RoDÓ, José ENRIQue. Obras completas. Emir Rodríguez Monegal edición, introducción, prólogos y notas. Madrid: Aguilar, 1967.

Rodríguez Monegal, Emir. "Prólogo a Motivos de Proteo". José Enrique Rodó. Obras completas. Madrid: Aguilar, 1967. 301-308.

Sánchez Prado, Ignacio. "Alfonso Reyes y el duelo de la historia". Intermitencias americanistas. Estudios y ensayos escogidos (2004-2010). México: UNAM, 2012.

SPITZER, LEO. "Das Eigene und das Fremde. Über Philologie und Nationalismus". Die Wandlung 1.7 (julio de 1946): 576-594.

Ugalde Quintana, Sergio. "Entre el ensayo y la filología: Alfonso Reyes, Cuestiones estéticas y el Ateneo de la Juventud". Sergio Ugalde Quintana y Ottmar Ette (eds.). Políticas y estrategias de la crítica: ideología, historia y actores de los estudios literarios. Madrid: Iberoamericana / Vervuert, 2016. 155-173.

VAlera OlEA, M. Ángeles. "Del modernismo a la vanguardia: Cervantes. Revista mensual ibero-americana (agosto 1916-diciembre 1920)". Cuadernos para la investigación de la literatura bispánica 23 (1998): 63-90.

ARCHIVOS

Archivo Histórico de la Capilla Alfonsina 